\title{
Anticonvulsant Therapy
}

National Cancer Institute

\section{Source}

National Cancer Institute. Anticonvulsant Therapy. NCI Thesaurus. Code C64172.

Drug treatment to prevent, stop, or reduce the severity of seizures or convulsions, commonly used in cases of epilepsy or other seizure disorders. 